\title{
Buying Turnout or Rewarding Loyalists? Electoral Mobilization and EU Structural Funding in the German Länder
}

\section{Dominik Schraff}

University of St. Gallen,

School of Economics and Political Science (SEPS),

Department of Political Science,

Rosenbergstrasse 51, 9000 St. Gallen, CH

dominik.schraff@unisg.ch

\begin{abstract}
This paper elaborates on the role of electoral mobilization in the allocation of EU structural funding. Revising the findings by Dellmuth and Stoffel (2012) on the German Länder, I show that stronghold regions with a high level of electoral mobilization receive more money. This strategy is conceptualized as 'rewarding loyalists'. I argue that due to temporally stable turnout levels, incumbents have incentives to favor stronghold regions with high turnout rates. Hence, incumbents use differences in the level of electoral mobilization to make distributive decisions among their many core constituencies. To test for spatial interdependencies and autocorrelation, I use a spatial autoregressive model as a robustness check. Even though the data shows spatial interdependencies, the results remain the same.
\end{abstract}

In a recent article Dellmuth and Stoffel (2012) find that German Länder governments favor core supporter regions in the allocation of EU funds. They show that Länder governments have substantial discretion in distributing funding. An analysis of EU structural fund allocations in the period 2000-6 reveals that NUTS3 regions with a higher vote share of the respective Prime Minister's party receive more funding. ${ }^{1}$ In this paper I argue that Dellmuth and Stoffel (2012) ignore a central dimension of Länder governments' vote-maximizing

\footnotetext{
1 The 'NUTS system' (nomenclature des unités territoriales statistiques) is used to systemize territorial levels in the European Union. In Germany, there are 429 NUTS3 regions (Landkreise and Kreisfreie Städte), 39 NUTS2 regions (Regierungsbezirke) and 16 NUTS1 regions (Länder).
} 
strategies - electoral mobilization. Accordingly, I show that a more comprehensive theoretical account - combining arguments on electoral mobilization with the core voter model - is necessary to explain the allocation process. Due to the many government strongholds in the German Länder, incumbents have to make further distributive decisions between those strongholds. Regional electoral mobilization seems to fulfill this function in the German context. The empirical analysis shows that there is a significant and positive interaction between the effect of the Prime Minister's party vote share and electoral turnout on regional funding.

Since this paper relates directly to Dellmuth and Stoffel's (2012) research, the paper follows the parameters set by their project. The study by Dellmuth and Stoffel (2012) analyzes the allocation of European Fund for Regional Development (EFRE) grants among 424 German NUTS3 regions. Controlling for socio-economic factors, such as GDP, unemployment, urbanization and geographical size, it is shown that German Länder governments reward their own electoral strongholds. Although recipient regions of EU funds generally seem to comply with the broad criteria laid down by the European Commission and the member states, official selection criteria cannot fully explain the variance in allocation patterns (Dellmuth and Stoffel, 2012). However, a central question which Dellmuth and Stoffel leave untouched is to whether electoral turnout matters for the allocation of EU funds. This paper takes up this question. In a first step, I will give a short summary the allocation process of EU funding in Germany.

\section{Länder Governments' Discretion in the Allocation of Funding}

To demonstrate the potential impact of sub-state electoral concerns on the 
allocation of structural funds in Germany one has to consider the negotiations accompanying EU structural funding. Germany's national funding budget is decided on the European level, with national governments, the European Commission and the European Parliament bargaining over the multi-annual financial perspective. Once the financial perspective is adopted, the Council passes a regulation specifying the provisions and objectives for the next funding period. When the absolute national funding level is set, the Commission, the national and the Länder governments negotiate on the allocation of funds across the regions.

A lot of the negotiations take place within informal meetings of working groups of Germany's second federal chamber (Bundesrat) (Dellmuth, 2011b). After that, the Länder come together in the conference of the Länders' ministers for economics and decide on an allocation key, taking into account several criteria such as economic performance or unemployment.

Following that, every Land starts identifying eligible regions within its territory and sets up an investment plan. This so called 'operational program' is negotiated with the European Commission and finally translated into European law (for a more detailed description of this process see Dellmuth, 2011b). Even though the Commission has a supervisory function in this process and tries to limit discretion through guidelines and working papers, Länder governments enjoy substantial leeway in designing their program and selecting beneficiaries. This is because the multi-annual financial framework of the EU and the final investment plans do not entailing clear-cut eligibility criteria (Dellmuth and Stoffel, 2012).

The final decision about projects being funded is taken in the responsible agencies within each Land and is through the executive hierarchy directly related to a Land's government. Furthermore, before an investment plan is set up, Land 
governments consult regional representatives to identify regions and projects eligible for funding (Dellmuth, 2011b). This more informal, preliminary stage in the funding process gives a lot of discretion to the government in selecting eligible regions.

Hence, it seems that governments of the German Länder enjoy a great level of autonomy in allocating EU funds within their territory. This autonomy is a result of broad selection criteria, a Land's independence in the selection of the final beneficiary and informal processes accompanying the allocation processes. The discretion resulting from this autonomy might allow Länder governments to use EU funds to follow their electoral interests. But what are the electoral interests of a government, which I term vote-maximizing strategies? The following section introduces theoretical approaches to this question.

\section{Vote-Maximizing Strategies}

Referring to prominent theoretical contributions on pork barrel politics in the US, research on intergovernmental grants usually tests the so called 'swing' and 'core' voter models (Cox and McCubbins, 1986; Dixit and Londregan, 1998; Lindbeck and Weibull, 1993). While those models were developed to analyze the allocation of benefits between single voters or groups of voters, they are also used to assess allocation patterns between territorial units (cf. Ansolabehere and Snyder, 2006).

Lindbeck and Weibull (1993) argue that incumbents at the federal level use their discretion in the allocation of funds to distribute more money to regions with a relatively high number of swing voters. Politicians at the central level have an incentive to increase their probability of re-election and therefore target benefits at highly contested regions. A study by Dahlberg and Johansson (2002) finds empirical support for the swing hypothesis. Analyzing data on government 
grants for ecological projects in Swedish municipalities, the authors show that municipalities with a larger share of swing voters receive more funding.

In contrast, Cox and McCubbins (1986) advance a model in which incumbents target funds at their core supporters. The underlying assumption here is that politicians are risk-averse and, therefore, try to rally and secure existing support. Accordingly, Solé-Ollé and Sorribas-Navarro (2008) show that regional transfers to Spanish municipalities are influenced by the alignment of the regional authorities with the central governing party. Dellmuth and Stoffel (2012) also identify similar patterns in the allocation of EU funding between German NUTS3 regions.

\section{The Role of Electoral Mobilization}

Empirical research, therefore, finds support for swing and core voter arguments. It seems that it depends on the specific context whether the swing voter model or the core voter model prevails. Cox (2010) argues that both approaches focus on persuasion as the mechanism behind vote buying, which is defined as an attempt to change voters' preferences. However, '[o]nce one brings coordination (defined as an attempt to affect the number and character of alternatives from which voters choose) and mobilization (defined as an attempt to affect whether or not citizens participate in the election) into analytic view, the argument that vote-maximizing parties should focus their distributive benefits on core voters is substantially strengthened' (Cox, 2010: 344). Using Dellmuth and Stoffel's (2012) data on EU funding in the German Länder, this paper aims at testing Cox's proposition on mobilization.

To begin, it is necessary to outline how Cox (2010) reaches his conclusion. Nichter's (2008) research about the role of electoral mobilization in vote-buying theories develops a strong rationale for Cox's argument. Even though this re- 
search focuses on the individual level, it can provide us with insightful cues for distributive politics on a regional level. Nichter shows that turnout is a crucial factor for governments' vote-maximizing strategies, arguing that it is unconvincing to talk about vote buying as an attempt to buy support (the actual vote), since the ballot is secret and incumbents effectively cannot monitor if people do vote for them. He reasons that incumbents, rather, try to buy turnout because this is easier to monitor. Two points make this argument theoretically compelling and strengthen the core voter model. First, effective monitoring works only with buying turnout, since this is a directly observable action. Second, if one accepts that vote-maximizing strategies aim at buying turnout, the government has strong incentives to target its efforts at supporters because only a higher turnout of supporters maximizes their vote gains. Nichter therefore infers that incumbents prefer to seek 'turnout buying' strategies. This strategy predicts that incumbents target benefits towards electorally immobilized supporters. In contrast to Nichter, I argue that in the context of the German Länder, incumbents have incentives to follow a strategy that rewards loyalists. The German case shows that moving from Nichter's individual level approach to an aggregated level can result in a strong rationale for, what Nichter calls, 'rewarding loyalists strategy'. The explanation for this result is as follows.

My argument builds on the core voter model's assumption of risk-averse politicians. Accordingly, I follow Cox (2010) in arguing that if incumbents are risk-averse, they have strong incentives to target benefits towards mobilized supporters. Incumbents could have an incentive to target benefits to mobilized supporters, since those are the most reliable voters with the highest electoral potential. Moreover, rewarding reliable voters could be attractive because investments in voters who are less likely to turn out might be wasted. The move from the individual to a constituency level of analysis makes this rationale especially 
strong. Imagine a situation where electoral turnout tends to be continuously lower in some regions than in others. Here, it would be reasonable to expect that incumbents anticipate this structural character of regional mobilization and concentrate their vote-maximizing strategies on high turnout regions. Considering differences in electoral turnout levels between German NUTS3 regions over time makes this argument particularly strong. Turnout patterns in the German NUTS3 regions seem to be relatively stable and certain NUTS3 regions consistently tend to have higher turnout rates than other NUTS3 regions.

To illustrate this point, I conducted an OLS regression estimating Bavarian turnout levels from the 2003 Landtag elections with turnout levels from the 1998 elections. $^{2}$ The effect of the 1998 turnout levels on later turnout is large, highly significant, and explains over $80 \%$ of the variance in the 2003 turnout. $^{3}$ Even though overall turnout declined in the past decades (Norris, 2002), mobilization differences between NUTS3 regions seem to remain. If one now considers that politicians anticipate this structural character of turnout for their vote-maximizing strategies, they have a strong incentive to target high turnout regions with benefits. Vote-maximizing strategies in low-turnout regions are wasted efforts since the expected vote gains are structurally smaller than in regions with higher turnout. This should be true especially for governments which are primarily interested in the overall vote share they get from an election, as it is the case for the German Länder governments.

Two recent studies confirm the connection between benefits and turnout. A study by De La O (2013) about a Mexican conditional transfer program shows that program enrollment led to an increase in turnout and an increase in the incumbent vote share. Similarly, an article by Chen (2013) shows that hurricane

\footnotetext{
${ }^{2}$ Bavaria is chosen because it is a big Land with a sufficient number of NUTS3 regions $(\mathrm{N}=96)$ to run a regression.

3 The coefficient on the 1998 turnout is 1.19 , with a standard error of 0.06 . The R-square is 0.85 .
} 
disaster aid in Florida increased the incumbent party's turnout. Individual-level evidence for increased turnout in those studies confirm Nichter's (2008) turnout buying strategy. However, it remains open if this rationale transfers to the allocation of benefits on a regional level, such as the European structural funds. Due to persisting differences in turnout between German NUTS3 regions, I argue that Länder governments follow a rewarding loyalist strategy. The resulting hypothesis expects incumbents to concentrate their vote-maximizing efforts on highly mobilized stronghold regions:

H: Regions with high electoral turnout and many government supporters receive more funding than comparable regions with low turnout ('rewarding loyalists' hypothesis).

This hypothesis expects a positive interaction between the number of government supporters and electoral mobilization. In other words, I expect that the core voter model is substantively strengthened by taking into account patterns of electoral mobilization.

\section{Research Design and Operationalization}

The empirical analysis uses the replication data-set provided by Dellmuth and Stoffel (2012). The data-set contains objective 1 and 2 payments from the European Fund for Regional Development (EFRE) during the funding period 2000-6. The data is available as aggregated funding levels of German NUTS3 regions. The exclusive focus on the EFRE is explained by limited data availability. However, the EFRE is the biggest and, therefore, most important EU fund. Any

finding on the EFRE is therefore likely to have a high level of generalizability to EU structural funding.

The dependent variable is the logarithm of structural funding per capita. This variable captures funding as a share of a region's population. Dellmuth 
and Stoffel (2012) use the logarithm of the variable to approximate a normal distribution. The core supporter hypothesis is measured by Dellmuth and Stoffel's (2012) variable 'voteshare', which provides data about the Land's Prime Minister's party vote share in each NUTS3 region before 1999. It is expected that voteshare has a positive effect on funding. The swing voter hypothesis is tested with Dellmuth and Stoffel's (2012) variable 'margin'. This variable captures how electorally contested a NUTS3 region is. This is measured by the difference in vote share between the first and the second strongest parties in the last Landtag election prior to 1999. Margin is expected to have a negative impact on funding, since funding should be targeted to regions with a small difference between the two major parties. The reliable voter hypothesis is tested with an interaction term of voteshare and electoral mobilization. Electoral mobilization is measured by levels of electoral turnout in the last Landtag election prior to 1999. It is expected that regions with a high share of the Prime Minister's party and high levels of electoral turnout receive more funding. To receive a meaningful coefficient on the interaction term, voteshare and turnout are centered on their respective means. ${ }^{4}$

Following Dellmuth and Stoffel (2012), the models include four socio-economic variables. GDP per capita, unemployment, geographical size and urbanization are used as control variables. Those variables have a strong theoretical foundation since they correspond to the socio-economic goals laid down in the guidelines of the European Commission (1999). All four variables are measured in 1999 to reflect the situation at the time the investment plan was drawn up. Geographical size is included because bigger regions are more likely to include declining rural areas than smaller regions. Hence, geographical size is a proxy for declining rural areas, about which no data is available on the NUTS3 level.

\footnotetext{
${ }^{4}$ Centring is done by a simple linear transformation of the two variables. Each variable is subtracted by its respective mean. After that the new zero points are average voteshare and average turnout.
} 
Furthermore, urbanization is used to account for the funding priority of urban areas in difficulties. The variable used by Dellmuth and Stoffel (2012) is therefore a dummy, indicating unity if a district comprises a city with more than 50,000 inhabitants.

\section{Results}

Since nearly $40 \%$ of the German NUTS3 regions did not receive any funding in 2000-6, I use - in line with Dellmuth and Stoffel (2012) - a Tobit regression to estimate the allocation of funds (Tobin, 1956). Standard errors are clustered by Länder to account for autocorrelation between NUTS3 regions of the same Land. Finally, standard errors are estimated robustly to account for heteroskedasticity. Due to randomly missing data in various variables, the sample size decreased from 424 NUTS3 regions to 399 . The only non-random cause for the missing data is a territorial reform in Sachsen-Anhalt. The final data-set of 399 regions is without missing data, which is required for the spatial models I will use for robustness checks. Since Tobit coefficients are not estimated linearly, they cannot be interpreted directly. In a first discussion I will, therefore, focus on the direction and the significance of the coefficients.

Model 1 of Table 1 presents a full model with all variables of interest. The interaction term is significant at the $5 \%$ level and points to the theoretically predicted direction. There is indeed a positive interaction between turnout and voteshare. Model 2 addresses an important issue in the data which was convincingly presented by Dellmuth and Stoffel (2012). As they show, there is a high correlation between margins and voteshare and model 1 , therefore, suffers from multicollinearity (Person's $\mathrm{r}=0.79, \mathrm{p}<0.01$ ). This is due to the fact that the swing hypothesis does not work for the German Länder. 
Table 1: Regression on EU funding per capita (log)

\begin{tabular}{|c|c|c|c|}
\hline & \multicolumn{2}{|c|}{ Tobit } & \multirow{2}{*}{$\begin{array}{c}\text { SPGMM } \\
(3)\end{array}$} \\
\hline & (1) & $(2)$ & \\
\hline \multirow[t]{2}{*}{ Voteshare } & 0.0664 & $0.150^{* * *}$ & $0.0896^{*}$ \\
\hline & $(0.112)$ & $(0.0396)$ & $(0.0481)$ \\
\hline \multirow[t]{2}{*}{ Margins } & -7.252 & & \\
\hline & $(11.22)$ & & \\
\hline \multirow[t]{2}{*}{ Turnout } & $0.184^{* *}$ & $0.161^{*}$ & $0.138^{* * *}$ \\
\hline & $(0.0858)$ & $(0.0829)$ & $(0.0429)$ \\
\hline \multirow[t]{2}{*}{ GDP per capita } & $-0.348^{* * *}$ & $-0.352^{* * *}$ & $-0.184^{* * *}$ \\
\hline & $(0.126)$ & $(0.123)$ & $(0.0393)$ \\
\hline \multirow[t]{2}{*}{ Urbanisation } & $3.788^{* * *}$ & $3.769^{* * *}$ & $0.716^{* * *}$ \\
\hline & $(0.943)$ & $(0.955)$ & $(0.0519)$ \\
\hline \multirow[t]{2}{*}{ Unemployment } & $0.839 * * *$ & $0.837^{* * *}$ & $1.417^{* * *}$ \\
\hline & $(0.154)$ & $(0.152)$ & $(0.467)$ \\
\hline \multirow[t]{2}{*}{ Geosize } & $2.124^{* *}$ & $2.248^{* *}$ & $2.056^{* *}$ \\
\hline & $(1.029)$ & $(0.966)$ & $(0.830)$ \\
\hline \multirow[t]{2}{*}{ Turnout*Voteshare } & $0.0120^{* *}$ & $0.00917^{* *}$ & $0.00906^{*}$ \\
\hline & $(0.00531)$ & $(0.00421)$ & $(0.00500)$ \\
\hline \multirow[t]{2}{*}{ Constant } & -0.544 & 0.750 & 1.622 \\
\hline & $(4.863)$ & $(3.685)$ & $(1.210)$ \\
\hline $\mathrm{N}$ & 399 & 399 & 399 \\
\hline Pseudo R2 & 0.11 & 0.10 & \\
\hline Adjusted R2 & & & 0.45 \\
\hline LM Lag (Anselin) & & & $4.75^{* *}$ \\
\hline
\end{tabular}

Robust standard errors in parentheses

$$
\text { *** } \mathrm{p}<0.01,{ }^{* *} \mathrm{p}<0.05,{ }^{*} \mathrm{p}<0.1
$$


Swing arguments assume that there are government and opposition strongholds and highly contested regions in the middle. However, in the data at hand, regions are either government strongholds or contested. Therefore, Dellmuth and Stoffel conclude that the two variables measure the same phenomenon. As model 2 shows, the results are not changed by taking out margins. The interaction effect is still positive and significant.

But how can we substantively interpret the interaction in model 2? To capture how turnout moderates the effect of voteshare on funding, Figure 1 plots the average marginal effect of voteshare over different levels of turnout. Voteshare becomes significant when there is a turnout of over $60 \%$. This is the case for 361 regions of the 399 in the model. This means that for a vast majority of cases in the data, there is a significantly positive linear interaction of voteshare and turnout on funding. On average, the effect of voteshare becomes stronger with increasing levels of turnout. Furthermore, about $10 \%$ of the cases have a critically low level of turnout which implies that for those cases, voteshare does not significantly affect funding.

Figure 1: Interaction of Prime Minister's vote share with electoral turnout

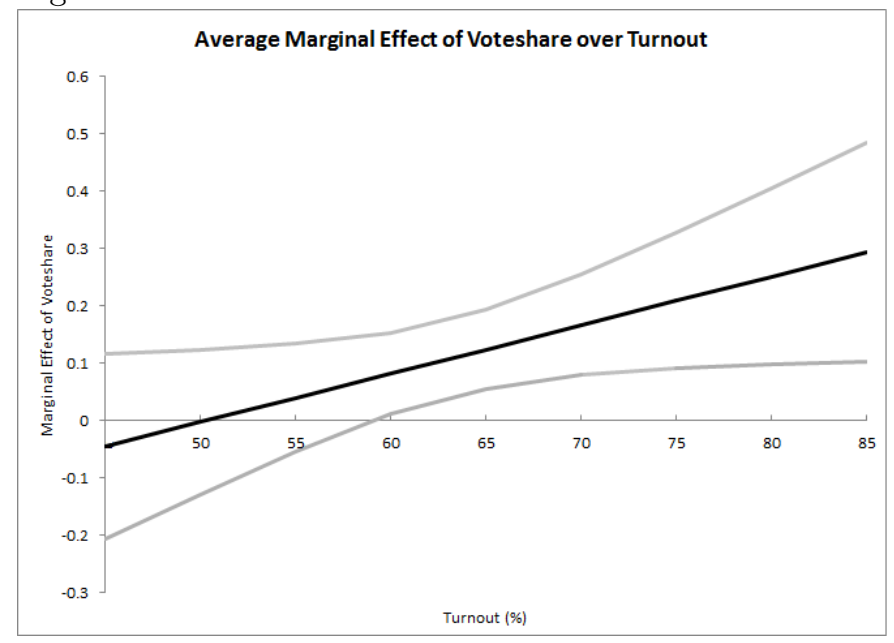

Dellmuth and Stoffel's original findings miss the central role of electoral 
turnout. Incumbents do not simply allocate money to supporters; they seem to discriminate between regions with high and low electoral turnout. This is an important finding given the high number of government strongholds in the German Länder. Figure 1 shows that electoral turnout is a crucial factor helping incumbents to make distributive decisions between their stronghold constituencies. Furthermore, this interaction leads to a more comprehensive and complex theoretical story which goes beyond classical core voter explanations.

The findings confirm Cox's (2010) general expectation that mobilization considerations further strengthen core voter arguments.

\section{Robustness Check}

The analysis above, as well as Dellmuth and Stoffel's (2012) research, ignores an important threat to the internal validity of the estimation strategy. With the exception of the clustered standard errors on the Land level, the analysis assumes statistical independence of the NUTS3 regions. Yet, it seems possible that the funding of a NUTS3 region is interdependent with regard to spatially close neighbor regions.

Figure 2 presents the total EFRE distribution among all German NUTS3 regions for the funding period 2000-6. Spatial patterns are easily identifiable, such as the structural fund accumulations in East Germany, East Bavaria or the Saarland. The Graph also presents turnout patterns in the German NUTS3 regions. In some regions high turnout seems to align with high funding, such as the Saarland or the South-West of Baden-Württemberg. Contrarily, in a number

of East German areas, for example, high funding levels seem to coincide with

low turnout. So, how could those spatial patterns threaten the validity of the results?

NUTS3 regions are territorially small units bordering a lot of other regions. 
It is possible that funding projects cross NUTS3 borders or that funding effects cross those borders. As funding effects are not exclusively restricted to NUTS3 borders, vote-maximizing strategies might cross those borders as well. Moreover, funding could be clustered on the level of NUTS2 regions.

Table 2: Spatial distribution of funding and turnout Total Funding (Million $€$ )
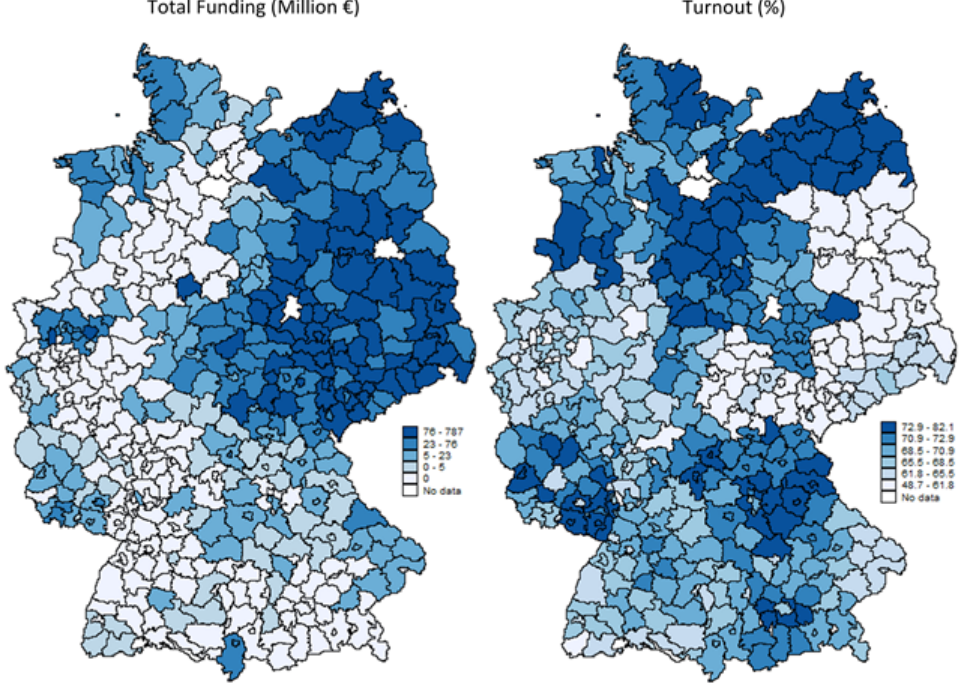

With regard to the specific effect of voteshare and turnout on funding, an important issue is that the clustering of funds in neighboring regions might align with macro-economic, historical or cultural conditions. High or low turnout could co-vary with such spurious conditions. If those spurious factors are geographically bound, spatial effects can control for that. Furthermore, it might be possible that funding in one region 'wakes' desires in a neighboring region. Seeing that a neighboring region from the same area receives certain funds could lead to increased demand for similar treatment. Such patterns of spending spillover effects and 'yardstick competition' found a lot of attention in literature on public spending and regional tax competition (cf. Foucault et al., 2008).

Since the 1970s, the inclusion of spatial effects finds regular application in econometric literature using panel or time-series data. Anselin and Florax 
(1995) introduced a prominent model which combines spatial lag dependence (funding in one region affects funding in another region) with spatial error dependence (an exogenous shock affects regions similarly). Kelejian and Prucha (1999) advanced this spatial modeling to cross-sectional data. Autocorrelation and disturbances across units of cases at one point in time is possible as well and this potential effect is often ignored in political science research. Especially in data using relatively small spatial units, such as NUTS3 regions, interdependencies and autocorrelation across units is very likely. To test the robustness of model 1 and 2 in Table 1 against spatial effects, I am going to use a spatial autoregressive cross-sectional model $(\mathrm{i}=1, \ldots, \mathrm{n})$ :

(1) $y_{i}=\lambda \sum_{j=1}^{n} \omega_{i j} y_{j}+\sum_{p=1}^{k} x_{i p} \beta_{p}+u_{i}$,

(2) $u_{i}=\rho \sum_{j=1}^{n} m_{i j} u_{j}+\varepsilon_{i}$

, where $\rho$ and $\lambda$ are the spatial autoregressive parameters for the $\omega y$ and $m u$ spatial lags.

The spatial effects are modeled as a contiguity matrix, which assumes that interdependencies and autocorrelations occur between neighboring regions. Hence, the weighting matrices $\omega$ and $m$ are created as $n \times n$ matrices, which are 0 if two regions have no common border and are 1 if regions share a common border (cf. Drukker et al., 2011). ${ }^{5}$ The average number of neighbors of a NUTS3 region in Germany is 3.6. A STATA software package by Shehata (2012) allows estimating Spatial Autoregressive Generalized Method of Moments (SPGMM) models with censored data (based on Kelejian and Prucha, 1999). The SPGMM models are again censored at zero and standard errors are robust and clustered at the Länder level.

Model 3 in Table 1 re-runs model 2 with spatial effects. The LM Lag Test

\footnotetext{
${ }^{5}$ Geographical data on German NUTS3 regions is derived from the European Environment Agency's homepage (http://www.eea.europa.eu/data-and-maps/data/administrativeland-accounting-units)
} 
reports that the spatial lagged dependent variable has spatial autocorrelation. This means that funding in one region tends to affect the funding level of neighboring regions. This could be due to one of the reasons mentioned above. Furthermore, it is also possible that funding is Objective specific and interdependencies reflect a similar objective status of neighboring regions. The SPGMM method qualifies as a more efficient estimation strategy. However, controlling for spatial effects does not change anything substantive in the results. There is still a significant, positive interaction and even the size of the coefficient is very similar. This should give us confidence in our results. Even though there are spatial interdependencies, they do not seem to compromise the effect of voteshare and turnout on funding.

\section{Conclusion and Discussion}

This paper re-assessed findings on the allocation of EU structural funds by Dellmuth and Stoffel (2012). Departing from a more refined theoretical story about core voter arguments and electoral mobilization, it could be demonstrated that electoral turnout plays a significant role in the allocation of funds.

The empirical findings support the rewarding loyalist hypothesis, which expects incumbents to target benefits towards highly mobilized stronghold regions. On average the effect of the vote share of the governing party on funding increases with higher levels of turnout. This means that Länder governments tend to allocate more money to government strongholds if the level of electoral turnout is high. Since the German data entails a relatively high number of government strongholds, the additional role of electoral turnout substantively enriches the explanation. Governments seem to use electoral mobilization as a discriminating factor between their many core constituencies. On a theoretical level, these findings imply that research on politicians' vote-maximizing 
strategies should supplement considerations regarding persuasion with arguments about electoral mobilization (Cox, 2010). Especially where differences of turnout levels between regions seem to be stable over time, the targeting of high turnout regions is logically conclusive. This runs counter to the individuallevel arguments presented by Nichter (2008) who favored the turnout buying hypothesis over rewarding loyalist arguments. This article showed that on an aggregated level and under the condition of relatively stable turnout rates, rewarding loyalists is more convincing than any other strategy.

An important caveat for this paper and similar research in the field (e.g. Bodenstein and Kemmerling, 2006, 2012; Dellmuth, 2011a; Dellmuth and Stoffel, 2012) refers to the cross-sectional nature of the analysis. It seems likely that there is a complex causal interaction between vote-maximizing efforts on the one hand and funding on the other. If, for example, current turnout affects funding in the next period, which in turn increases turnout in subsequent periods, we would have an issue of reversed causality which cannot be convincingly addressed with this kind of data. The theoretical account of the rewarding loyalist strategy does not have to be compromised by this because it assumes that funding serves as a means to secure existing support. Funding, therefore, is not expected to increase turnout levels. However, to test such assumptions, further research should try to obtain data from several funding periods.

\section{Acknowledgments}

For helpful comments and advice on previous drafts I would like to thank

Lisa Dellmuth, Patrick Emmenegger, Dirk Lehmkuhl, Slava Mikhaylov and two anonymous reviewers. I also would like to thank all participants of the Political Science Research Seminar at the University of St. Gallen. 


\section{References}

[1] Anselin L and Florax RJGM (1995) Introduction. In: Anselin L and Florax RJGM (eds) New Directions in Spatial Econometrics. Berlin: Springer, pp. $3-18$.

[2] Ansolabehere S and Snyder JM (2006) Party Control of State Government and the Distribution of Public Expenditures. Scandinavian Journal of Economics 108(4): 547-569.

[3] Bodenstein T and Kemmerling A (2006) Partisan politics in regional redistribution: Do parties affect the distribution of EU structural funds across regions? European Union Politics 7(3): 373-392.

[4] Bodenstein T and Kemmerling A (2012) Ripples in a rising tide: Why some EU regions receive more structural funds than others. European Integration online Papers 16(1), Article 1 (http://eiop.or.at/eiop/texte/2012001a.htm, accessed May 2013).

[5] Chen J (2013) Voter partisanship and the effect of distributive spending on political participation. American Journal of Political Science 57(1): 200217.

[6] Cox GW (2010) Swing voters, core voters and distributive politics. In: Shapiro I, Stokes S, Wood E and Kirshner AS (eds) Political Representation. Cambridge: Cambridge University Press, pp. 342-357.

[7] Cox GW and McCubbins MD (1986) Electoral politics as a redistributive game. Journal of Politics 48(2): 370-389.

[8] Dahlberg M and Johansson E (2002) On the vote-purchasing behaviour of incumbent governments. American Political Science Review 96(1): 27-40.

[9] De La O A (2013) Do conditional cash transfers affect electoral behaviour? 
Evidence from a randomized experiment in Mexico. American Journal of Political Science 57(1): 1-14.

[10] Dellmuth LM (2011a) The cash divide: The allocation of European Union regional grants. Journal of European Public Policy 18(7): 1016-1033.

[11] Dellmuth LM (2011b) European structural, agricultural and environmental spending in Germany: The allocation and implementation of EU resources. Policy Paper for MEP Franziska Brantner. Stockholm University.

[12] Dellmuth LM and Stoffel M (2012) Distributive politics and intergovernmental transfers: The local allocation of European Union Structural Funds. European Union Politics 13(3): 413-433.

[13] Dixit A and Londregan J (1998) Fiscal federalism and redistributive politics. Journal of Public Economics 68(2): 153-180.

[14] Drukker DM, Prucha IR and Raciborski R (2011) Maximum-likelihood and generalized two-stage least-squares estimators for spatial-autoregressive models with spatial-autoregressive disturbances. Working Paper, Department of Economics, University of Maryland.

[15] European Commission (1999) Council regulation for the general provision of structural funds 2000-6. Council Regulation (EC) No 1260/1999.

[16] Foucault M, Madies T and Paty S (2008) Public spending interactions and local politics. Empirical evidence from French municipalities. Public Choice 137(1-2): 57-80.

[17] Kelejian HH and Prucha IR (1999) A generalized moments estimator for the autoregressive parameter in a spatial model. International Economic Review 40(2): 509-533. 
[18] Lindbeck A and Weibull JW (1993) A model of political equilibrium in a representative democracy. Journal of Public Economics 51(2): 195-209.

[19] Nichter S (2008) Vote buying or turnout buying? Machine politics and the secret ballot. American Political Science Review 102(1): 19-31.

[20] Norris P (2002) Democratic Phoenix: Reinventing Political Activism. Cambridge: Cambridge University Press.

[21] Shehata EAE (2012) SPAUTOREG: stata module to estimate spatial cross sections regression models: (SAR-SEM-SDM-SAC-SARARGS-SARARIVSARARML-SPGMM-GS2SLS-GS2SLSAR-GS3SLS-GS3SLSAR-

IVTOBIT). Statistical Software Components S457338, Boston College Department of Economics, revised 18 Jun 2012.

[22] Solé-Ollé A and Sorribas-Navarro P (2008) The effects of partisan alignment on the allocation of intergovernmental transfers. Differences-in-differences estimates for Spain. Journal of Public Economics 92(12): 2302-2319.

[23] Tobin J (1956) Estimation of relationships for limited dependent variables. Econometrica 26(1): 24-36. 